\title{
Decay of Populus cathay Treated with Paraffin Wax Emulsion and Copper Azole Compound ${ }^{1}$
}

\author{
Jie $\operatorname{Liu}^{2} \cdot \operatorname{Min} \mathrm{Liu}^{2} \cdot$ Bingyi $\mathrm{Hou}^{2} \cdot$ Erni Ma $\mathbb{D}^{2, \dagger}$
}

\begin{abstract}
In order to investigate the decay process of wood treated with preservative, waterproofing agent and their compound systems, a full-cell process was applied to impregnate the sapwood of poplar (Populus cathay) at paraffin wax emulsion concentrations of $0.5 \%$ and $2.0 \%$, Copper Azole (CA) concentrations of $0.3 \%$ and $0.5 \%$, and their four compound systems, respectively. Leaching tests and laboratory decay resistance against the white-rot fungus Corious versicolor (L.) Murrill for treated wood were carried out according to the America Standard E11-06 and China Standard GB/T 13942.1-2009. At certain time intervals during the decay test, samples were characterized by Fourier transform infrared spectroscopy (FTIR) and X-ray diffraction technique (XRD) to investigate the time-dependent changes of chemical components and crystalline structure, thus clarifying the decay mechanisms. The results suggested that white-rot fungi degrade hemicellulose and lignin in the wood cell wall first, followed by a simultaneous degradation of polysaccharides and lignin. Besides, CA could not only slower the decomposition of both hemicellulose and lignin, but also reduce the degradation amount of hemicellulose. However, paraffin wax emulsion at high concentration had a negative effect on the impregnation of CA for the compound system treated wood.
\end{abstract}

Keywords: Copper Azole, paraffin wax emulsion, compound system, laboratory decay resistance, wood

\section{INTRODUCTION}

Wood, as a natural material, has various excellent properties and has been extensively utilized over centuries. However, wood is easily subjected to biodeterioration caused by microorganisms (Cao and Yu, 2010; Lee et al., 2017; Won et al., 2016; Won et al., 2017), which greatly limits its utilization. An effective way to provide wood with decay resistance in practice is by treating with preservative (Humar and Lesar, 2008; Kartal et al., 2015; Lee et al., 2016; Sen et al., 2009). As a widely used water-borne preservative with outstanding properties, Copper Azole (CA) is not waterproof (Tascioglu and Tsunoda, 2010; Tang et al., 2013). As a result, cracking and warping of CA treated wood always take place, and thus the leaching of preservative occurs. Therefore, a compound treatment on wood with both preservative and water repellent is an efficient consideration to enhance the dimensional stability of water-borne preservative treated wood. There has been several reports concerning this. Specifically, in the 1990s, foreign researchers started

${ }^{1}$ Date Received September 19, 2018, Date Accepted December 21, 2018

2 Beijing Key Laboratory of Wood Science and Engineering, MOE Key Laboratory of Wooden Material Science and Application, Beijing Forestry University, Beijing, 100083, China

† Corresponding author: Erni Ma (e-mail: maerni@bjfu.edu.cn, ORCID: 0000-0001-9774-9779) 
Jie Liu $\cdot$ Min Liu $\cdot$ Bingyi Hou $\cdot$ Erni Ma

to add water repellent into preservative to impregnate wood (Yang et al., 2016). More recently, the wood preservative industry in China tried to combine waterproofing agent with preservative to modify wood for outdoor applications (Chen et al., 2009). Wang et al. (2011) treated Pinus massoniana Lamb. with waterproofing agent and preservatives simultaneously and found that water repellency and wet-resistant rates of modified wood were greatly improved. Besides, Lesar et al. (2011) pointed out that wood impregnated with both water repellent (wax emulsion) and preservatives (boron compounds) was protected against decay effectively.

In our previous research, environmentally friendly paraffin water repellent was prepared based on natural surfactants of alkyl glycoside and span (Wang et al., 2018). It was proved that wood treated by this repellent with CA had a good performance of water resistance and dimensional stability (Wang et al., 2014), metal corrosion resistance (Wang et al., 2015), anti-mould and anti-blue stain (Zhong et al., 2014) and decay resistance (Liu et al., 2018). Interactions among the waterproofing agent, preservative, and wood were further investigated by stress relaxation approach (Liao et al., 2016). However, the leachability and its effect on decay process of treated wood have not been characterized yet.

Generally, the decay resistance is mainly evaluated by the mass loss of wood. Namely, the amount of wood components including cellulose, hemicellulose, and lignin will be reduced due to fungal infection (Bari et al., 2015; Liu et al., 2018). However, this traditional method only reflects the change of quality before and after wood decay rather than microscopic alterations in wood. Fourier transform infrared spectroscopy (FTIR), a favorable methodology for analyzing functional groups and chemical structures of materials, is fast and highly sensitive, which has been widely applied in the researches of wood science including the early diagnosis of wood biodeterioration (Wang et al., 2009). For instance, Li et al. (2010) studied the chemical changes of masson pine (Pinus masso-niana lamb.) infected by brown-rot fungi with FTIR, and confirmed that FTIR could be used to accurately investigate the content of holocellulose and Klason lignin during the decay process. Fackler et al. (2011) provided evidence for white-rot decay process in wood cell walls using FTIR microscopy. However, the destruction of cellulose could not be fully understood by FTIR. X-ray diffraction technique (XRD), being capable of detecting the crystalline structure in cellulose, can be used to analyze the variation of cellulose crystallinity. Therefore, it is an effective way to follow the changes of the main components in wood cell walls, and therefore the functions of the compound system against decay during biodegradation process by combining FTIR with XRD.

The objective of this work was to characterize the laboratory decay resistance of poplar wood treated with the compound system of paraffin emulsion and CA. The influence of leachability on the decay resistance against white rot fungi of the treated wood was evaluated by the mass loss. To interpret the decay mechanism and effects of the compound system, especially for the early stage, FTIR and XRD were employed to obtain time-dependent changes of functional groups and crystallinity of chemical components in wood cell walls during the decay process. This research was undertaken to provide the scientific basis and techniques required support for the development of waterproofing preservatives, which is of great importance to achieve high efficiency and high value-added utilization of fast growing wood.

\section{MATERIALS and METHODS}

\subsection{Materials}

Poplar (Populus cathayana), a fast growing wood 
Table 1. Group of wood samples

\begin{tabular}{cccc}
\hline Samples & Group & Concentration of paraffin emulsion & Concentration of CA \\
\hline \hline Control & Control & 0 & 0 \\
\hline \multirow{2}{*}{ CA treated wood } & $0.3 \% \mathrm{C}$ & 0 & $0.3 \%$ \\
& $0.5 \% \mathrm{C}$ & 0 & $0.5 \%$ \\
\hline \multirow{2}{*}{ Paraffin emulsion treated wood } & $0.5 \% \mathrm{~W}$ & $0.5 \%$ & 0 \\
& $2.0 \% \mathrm{~W}$ & $2.0 \%$ & 0 \\
\hline \multirow{2}{*}{ Compound system treated wood } & $0.5 \% \mathrm{~W} / 0.3 \% \mathrm{C}$ & $0.5 \%$ & $0.3 \%$ \\
& $0.5 \% \mathrm{~W} / 0.5 \% \mathrm{C}$ & $0.5 \%$ & $0.5 \%$ \\
& $2.0 \% \mathrm{~W} / 0.3 \% \mathrm{C}$ & $2.0 \%$ & $0.3 \%$ \\
\hline
\end{tabular}

in north China, was chosen as the test species. The sapwood, free of obvious defects (decay and knot), was used and cut into samples with the size of $20 \mathrm{~mm}$ (T) $\times 20 \mathrm{~mm}(\mathrm{R}) \times 10 \mathrm{~mm}(\mathrm{~L})$. The density was 0.38 $\mathrm{g} / \mathrm{cm}^{3}$, with moisture content of $8-12 \%$ in an air-dried state.

Wood preservative was CA, purchased from Guangzhou Xingyue Wood Preservative Limited Company in China. The main components were copper and triazole at $9.98 \%$ and $0.42 \%$, with active ingredient content being $10.4 \%$ in total. Use category of C3 (outdoor without soil contact) and C4A (outdoor with soil contact) were applied in this study. According to the American Wood Protection Association Standards (AWPA U1-08, 2008), the minimal retention levels of CA for the two conditions used were $1.7 \mathrm{~kg} / \mathrm{m}^{3}$ and $3.3 \mathrm{~kg} / \mathrm{m}^{3}$ respectively, corresponding to concentrations of $0.3 \%$ and $0.5 \%$ determined by a pretest, labeled as $0.3 \% \mathrm{C}$ and $0.5 \% \mathrm{C}$.

Paraffin wax emulsions, as the water repellent, were prepared in the laboratory based on natural surfactants of alkyl glycoside and span at solid content of 25\% (Wang et al., 2018). Two concentrations of paraffin wax emulsion selected in this work were $0.5 \%$ and $2.0 \%$, labeled as $0.5 \% \mathrm{~W}$ and $2.0 \% \mathrm{~W}$. This resulted in four uniform and stable compound systems prepared by physically mixing CA, paraffin wax and deionized water, labeled as $0.5 \% \mathrm{~W} / 0.3 \% \mathrm{C}, \quad 0.5 \% \mathrm{~W} / 0.5 \% \mathrm{C}$, $2.0 \% \mathrm{~W} / 0.3 \% \mathrm{C}, 2.0 \% \mathrm{~W} / 0.5 \% \mathrm{C}$ shown in Table 1.

Coriolus versicolor (L.) Murrill, as the typical white-rot fungi in China, chosen as the experimental fungus in this work was purchased from the Chinese Academy of Forestry.

\subsection{Methods}

\subsubsection{Wood impregnation treatment}

The samples were first oven-dried at $103{ }^{\circ} \mathrm{C}$ to constant mass W1 (g). Then a full-cell process was applied one-time to treat the samples by CA, paraffin emulsion, and their compound systems. Specifically, they were exposed to a vacuum condition of $-0.1 \mathrm{MPa}$ for 30 minutes, followed by a pressure of $2 \mathrm{MPa}$ for $1 \mathrm{~h}$. After impregnation, the samples were taken out, and liquid on the surface was wiped away by blotting paper. The treated samples were kept for two days at room temperature. Finally they were oven-dried at $103{ }^{\circ} \mathrm{C}$ to constant mass W2 (g). Weight percent gain (WPG) of the treated wood was calculated by Equation (1).

$$
\mathrm{WPG}(\%)=(\mathrm{W} 2-\mathrm{W} 1) / \mathrm{W} 1 \times 100
$$

\subsubsection{Leachability test}

Leachability of CA as well as the compound system treated wood was determined according to the standard 
of E11-06 issued by AWPA (AWPA E11-06, 2006). Specifically, the samples were first immersed in 300 $\mathrm{ml}$ deionized water in a beaker and agitated with a magnetic stirrer bar at $3000 \mathrm{rmp} / \mathrm{min}$. The leachate was removed and replaced after $6,24,48 \mathrm{~h}$ and thereafter every 48 hours with the same amount of deionized water. The samples were leached in total for 14 days and their content of $\mathrm{Cu}$ before and after the leaching was measured by ICP-AES (Perkin 5300V, USA) after acid digestion according to AWPA standard A21-14 to determine percentage copper release (AWPA A21-14, 2014) The $\mathrm{Cu}$ leaching rate (LR) was calculated by Equation (2).

$$
\mathrm{LR}(\%)=(\mathrm{L} 1-\mathrm{L} 2) / \mathrm{L} 1 \times 100
$$

Where L1 and L2 represent cooper content before and after leaching respectively.

\subsubsection{Laboratory decay resistance test}

Laboratory decay resistance test was conducted according to China Standard GB/T 13942.1-2009. A $300 \mathrm{ml}$ cylindrical culture bottle with a plastic screw lid was used as the decay chamber, containing the following ingredients uniformly mixed as: $150 \mathrm{~g}$ of sand, $75 \mathrm{~g}$ of wood powder, $4.3 \mathrm{~g}$ of corn flour, and $0.5 \mathrm{~g}$ of brown sugar. Two feeder strips of poplar with the size of $25 \mathrm{~mm} \times 25 \mathrm{~mm} \times 3 \mathrm{~mm}$ were placed on the top of the mixture, and $8 \%$ malt solution was added into the bottle which was autoclaved for $60 \mathrm{~min}$ at $121{ }^{\circ} \mathrm{C}$ for sterilization. White-rot fungi was inoculated on the edge of the feeder strip in the medium under aseptic conditions. The entire mixture was kept at constant temperature $\left(25 \pm 2{ }^{\circ} \mathrm{C}\right)$ and humidity $(65 \%$ $-75 \%$ ) for 2 weeks. When the hyphae grew to cover the two feeder strips, test samples were autoclaved for $30 \mathrm{~min}$ at $103{ }^{\circ} \mathrm{C}$ and placed in the medium for 12 weeks. Each bottle had two replicates that were on the top of the strips. As shown in Table 1, all the nine groups of wood samples were tested for decay resistance
Table 2. Evaluation criteria for laboratory test of wood decay resistance in China

\begin{tabular}{ccc}
\hline & Wood decay resistance grade & Mass loss \\
\hline \hline I & Very durable & $0 \sim 10 \%$ \\
II & Durable & $11 \% \sim 24 \%$ \\
III & Slightly durable & $25 \% \sim 44 \%$ \\
IV & Non durable & $>45 \%$ \\
\hline
\end{tabular}

and six replicates were used in each group. In addition, three of the groups (Control, $0.5 \% \mathrm{C}, 2.0 \% \mathrm{~W} / 0.5 \% \mathrm{C}$ ) were added six more blocks for decay process characterization. According to China Standard GB/T 13942.1-2009, wood decay resistance is divided into four grades based on the mass loss as shown in Table 2 .

\subsubsection{FTIR analysis}

The samples were crushed into 60-80 mesh powders and oven-dried at $103{ }^{\circ} \mathrm{C}$. The powders were mixed with potassium bromide $(\mathrm{KBr})$ which was used to correct the background and oven-dried at $120{ }^{\circ} \mathrm{C}$ as well, at a ratio of 1:10. The mixture was pressed into thin slices with a pressure of $4 \mathrm{MPa}$ and monitored by FTIR (Bruker Vertex 70v, Germany). The scanning range was $1000-3500 \mathrm{~cm}^{-1}$ with a resolution of $4 \mathrm{~cm}^{-1}$, and the scanning number was 32 times.

\subsubsection{XRD analysis}

60-80 mesh sample powders were oven-dried at 103 ${ }^{\circ} \mathrm{C}$ and characterized by XRD (Bruker D8 ADVANCE, Germany) at scanning angle of $5^{\circ}-40^{\circ}(2 \theta)$ and scanning speed of $4 \% \mathrm{~min}$. Crystallinity of the samples was acquired by using Segal empirical formula (Li et al., 2017).

\section{RESULTS and DISCUSSION}

\subsection{Mass loss}

Weight percent gain and mass loss after decay 
Table 3. Weight percent gain and mass loss rate of the samples.

\begin{tabular}{ccccc}
\hline Samples & Group & Weight percent gain/\% & Mass loss/\% & Durability class \\
\hline \hline Control & Control & 0 & $64.40 \pm 8.86$ & Non durable \\
\hline \multirow{2}{*}{ CA treated wood } & $0.3 \% \mathrm{C}$ & $1.54 \pm 0.11$ & $4.14 \pm 0.28$ & Very durable \\
\hline \multirow{2}{*}{$\begin{array}{c}\text { Paraffin emulsion } \\
\text { treated wood }\end{array}$} & $0.5 \% \mathrm{C}$ & $1.85 \pm 0.05$ & $4.09 \pm 0.34$ & \multirow{2}{*}{ Non durable } \\
\hline \multirow{2}{*}{$\begin{array}{c}\text { Compound system } \\
\text { treated wood }\end{array}$} & $0.5 \% \mathrm{~W}$ & $0.45 \pm 0.09$ & $54.74 \pm 2.12$ & $54.10 \pm 2.13$ \\
& $2.0 \% \mathrm{~W}$ & $1.79 \pm 0.10$ & $2.88 \pm 0.14$ & Very durable \\
\end{tabular}

aafterleaching

resistance testing for the treated samples are listed in Table 3. It is clear that the weight percent gain increases with the increase of treating concentration.

As shown in Table 3, the Control exhibited the maximum mass loss of $64.4 \%(\mathrm{p}<0.05)$, followed by paraffin wax emulsion treated wood, both corresponding to durability class of "non durable". The results support the report by Liu et al. (2018). Fortunately, after CA or compound system impregnation, the durability class of treated samples became "very durable", proving CA and its treated wood had excellent performances after leaching. Compared with CA treated wood, the mass losses of compound system treated wood at $0.5 \%$ paraffin wax emulsion were lower ( $>0.05)$, while the opposite result was obtained for the $2.0 \%$ paraffin wax emulsion ( $p>0.05$ ), indicating that paraffin water repellent at high concentration may have a negative effect on the impregnation of CA for the compound system treated wood (Wang et al., 2018; Liu et al., 2018).

\subsection{Cu Leaching rate}

As shown in Fig. 1, the $\mathrm{Cu}$ leaching rate of high concentration CA treated wood $(0.5 \% \mathrm{C})$ was more than twice as much as that of low concentration $(0.3 \% \mathrm{C})$.

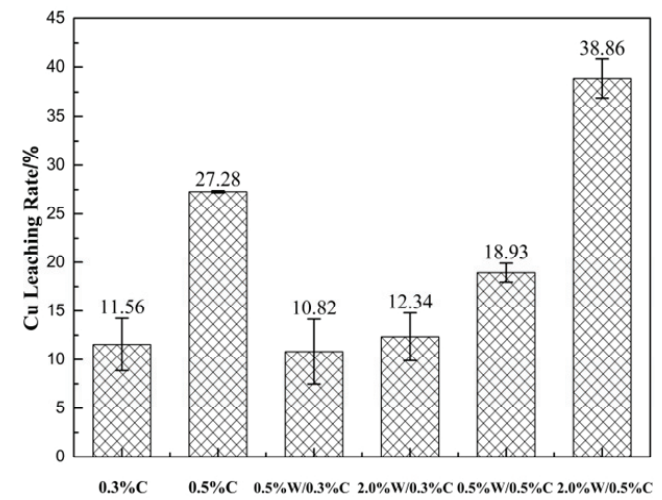

Fig. 1. Leaching rate of CA and compound system treated wood.

The $\mathrm{Cu}$ leaching rates increased with an increase in the concentration of CA, which is consistent with the result of Lin et al. (2009).

The reason being that the fixation rate of CA is greatly affected by its concentration. Specifically, the fixation rate of cooper in preservative with high CA concentration is lower than that with low CA concentration (Wang et al., 2013; Jiang and Zhang, 2008). As the fixation rate increases, the $\mathrm{Cu}$ leaching rate decreases. The $\mathrm{Cu}$ leaching rates of compound system treated wood with the concentration of $0.5 \%$ paraffin $(0.5 \% \mathrm{~W} / 0.3 \% \mathrm{C}, 0.5 \% \mathrm{~W} / 0.5 \% \mathrm{C})$ were lower than both corresponding CA treated wood, while those 


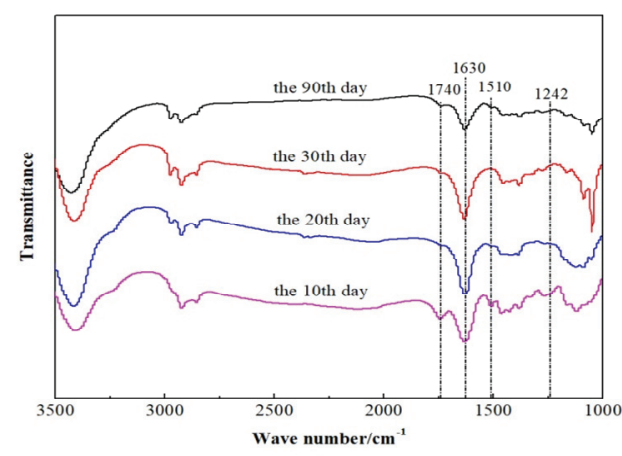

(a)

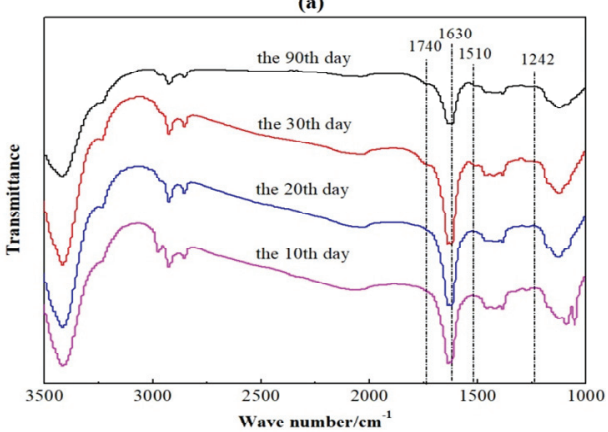

(b)

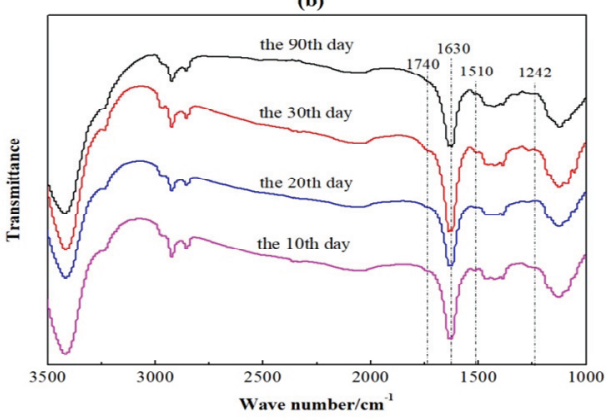

(c)

Fig. 2. FTIR of samples during the decay process. (a) Control. (b) $0.5 \%$ C. (c) $2.0 \% \mathrm{~W} / 0.5 \% \mathrm{C}$.

of compound system treated wood with the concentration of $2.0 \%$ paraffin $\quad(2.0 \% \mathrm{~W} / 0.3 \% \mathrm{C}$, $2.0 \% \mathrm{~W} / 0.5 \% \mathrm{C}$ ) gave the opposite trend, which suggests that the addition of water repellent at $0.5 \%$ concentration level plays a positive role in waterproofing during the process of leaching, whereas in case of compound system treated wood at higher concentration of water repellent, the paraffin emulsion was impregnated into wood to form a layer of wax outside the cell wall (Wang et al., 2015; Liu et al., 2018), hindering CA entering wood cell wall, which leads to a significant reduction in fixation rate of CA. This result of $\mathrm{Cu}$ leaching rate for compound system treated wood at two kinds of paraffin emulsion concentrations is consistent with that of mass losses.

\subsection{FTIR analysis}

The FTIR spectrum is usually divided into three bands, $3500-2700 \mathrm{~cm}^{-1}, 2700-1800 \mathrm{~cm}^{-1}$, and 1800-1000 $\mathrm{cm}^{-1}$ where main functional groups from holocellulose and lignin of wood are involved (Huang et al., 2015; Wang et al., 2014; Chi, 2005). The spectra for the samples of control, $0.5 \% \mathrm{C}$ and $2.0 \% \mathrm{~W} / 0.5 \% \mathrm{C}$ after decay by white-rot fungi are shown in Fig. 2 and Fig. 4.

The different characteristic peaks represent functional groups of hemicellulose and lignin, i.e., the peak of $1740 \mathrm{~cm}^{-1}$ attributes to non-conjugated $\mathrm{C}=\mathrm{O}$ stretching vibration absorption peak of hemicellulose, $1630 \mathrm{~cm}^{-1}$ and $1510 \mathrm{~cm}^{-1}$ corresponds to conjugate carbonyl $\mathrm{C}=\mathrm{O}$ stretching vibration and carbon skeleton vibration from the aromatic ring of lignin, and $1242 \mathrm{~cm}^{-1}$ belongs to the peak of lignin guaiac. As shown in Fig. 2a, b and c, the peak intensities of $1740 \mathrm{~cm}^{-1}, 1510 \mathrm{~cm}^{-1}$, and $1242 \mathrm{~cm}^{-1}$ decreased during the decay process, which indicates the chemical components of hemicellulose and lignin were degraded, which is in favor of Pandey and Pitman (2003), Pandey and Nagveni (2007) and Liu et al. (2018). Therefore, the weight of samples after decay dropped as suggested by mass losses.

The intensities of $1740 \mathrm{~cm}^{-1}$ and $1242 \mathrm{~cm}^{-1}$ which were transferred from the absorbance of infrared scanning are shown in Fig. 3. The maximum intensity was taken as 1 and other values are the ratio of the maximum. In Fig. 3a, the intensity of $1740 \mathrm{~cm}^{-1}$ peak of the Control decreased significantly from the 10th to 30th day, indicating that the content of carbonyl 
Decay of Populus cathay Treated with Paraffin Wax Emulsion and Copper Azole Compound

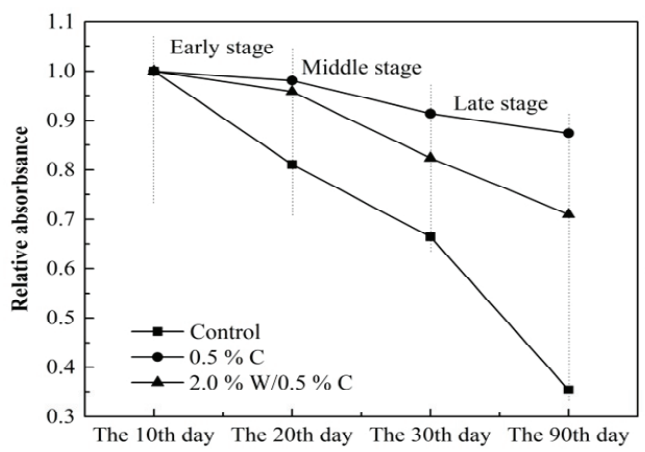

(a)

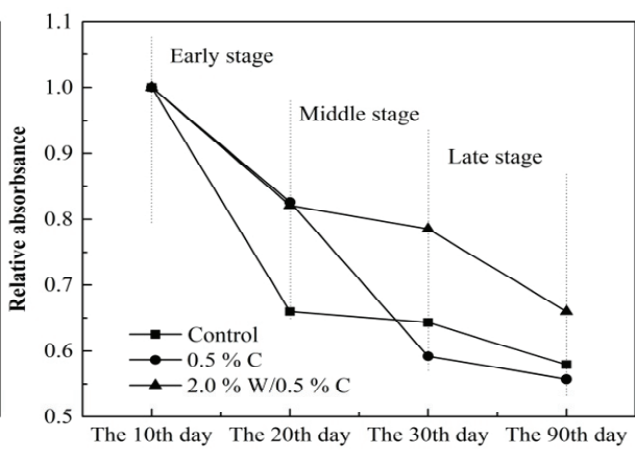

(b)

Fig. 3. Relative absorbance at $1740 \mathrm{~cm}^{-1}$ (a) and $1242 \mathrm{~cm}^{-1}$ (b) of Control, CA and compound system treated wood during decay process.

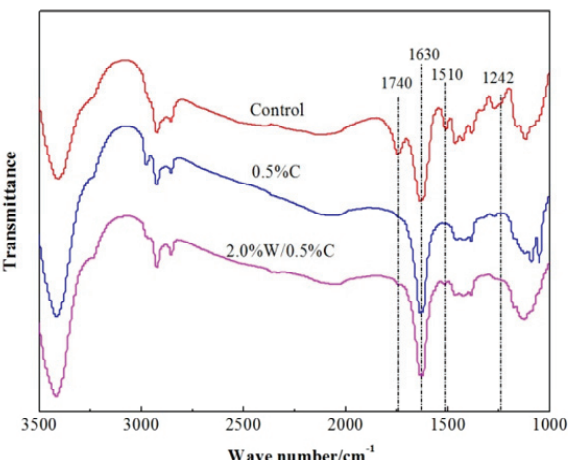

(a)

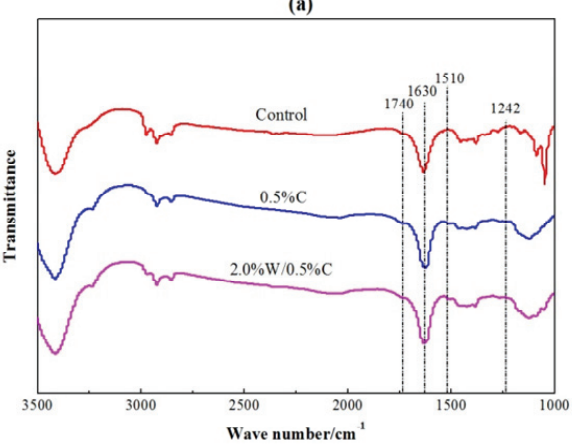

(c)
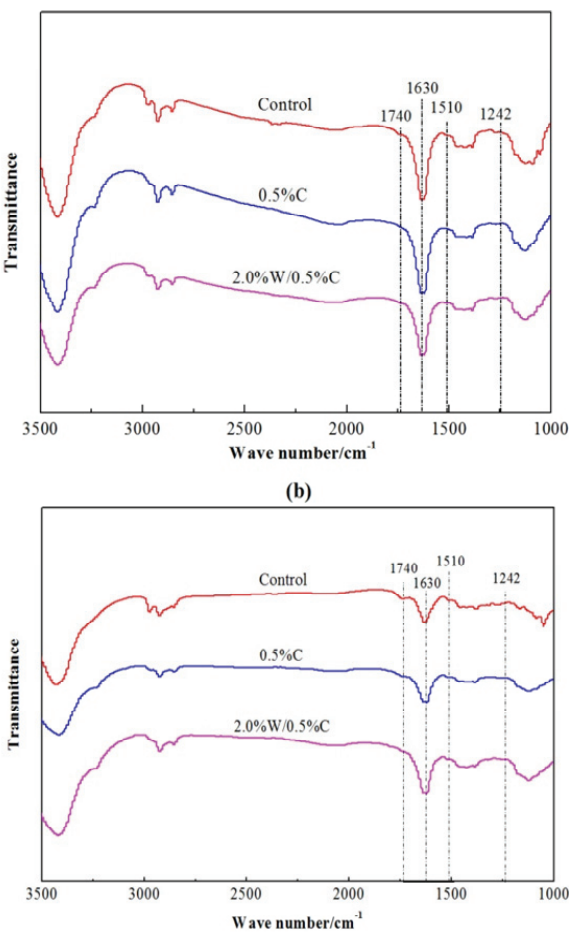

(d)

Fig. 4. FTIR of samples on the 10th (a), 20th (b), 30th (c), and 90th (d) day during decay process.

was reduced, and xylan in hemicellulose was partly degraded (Lin et al., 2010; Pandey and Pitman, 2010).

This peak intensity also decreased from the 30th to 90th day, showing that hemicellulose decomposed not only in early and middle stage, but also in late stage during the decay process. Compared with the Control, 
the peak intensity of CA and compound system treated wood decrease slightly in both early stage and middle stage, illustrating that CA could reduce the decomposition speed of hemicellulose. At the same time, the intensity of the Control during the late stage was much lower than that of CA and compound system treated wood, illustrating that CA could reduce the degradation amount of hemicelluloses. Besides, it is found that the decay resistance effect of compound system treated wood is not better than that of CA treated wood, suggesting the higher mass loss of the Control could be partly caused by the degradation of hemicellulose. According to Wang et al. (2006), hemicellulose breaks down into small molecular acids (such as glucose acid, lactic acid, etc.) or lipids (glucose esters), which are directly used by the white-rot fungi during the process of degradation.

The variety of $1242 \mathrm{~cm}^{-1}$ during decay process is presented in Fig. 3b. The intensity of guaiacyl lignin of the Control was clearly reduced in the early stage, and decreased slightly from the 20th day to the 90th day, which indicates that lignin was degraded extensively in early stages of decay. The long chain hydrocarbon of lignocellulosics was cut into small molecules, and the ring structure was gradually decomposed into chain compounds (Wang et al., 2006). The degradation degree of CA treated wood and compound system treated wood is lighter than the Control in early stage. Therefore, CA could slower the degradation of lignin. The intensity of lignin guaiac of compound system treated wood decreases clearly in early stage compared with the middle and late stage, in accordance with the Control, but the intensity on the 90th day is higher than that of the Control. On the other hand, the final degradation amount of lignin of CA treated wood is much more than the Control.

The FTIR spectra of samples on the 10th day during the decay process is shown in Fig. 4a. The peak intensity of $1740 \mathrm{~cm}^{-1}$ of CA treated wood is much lower than

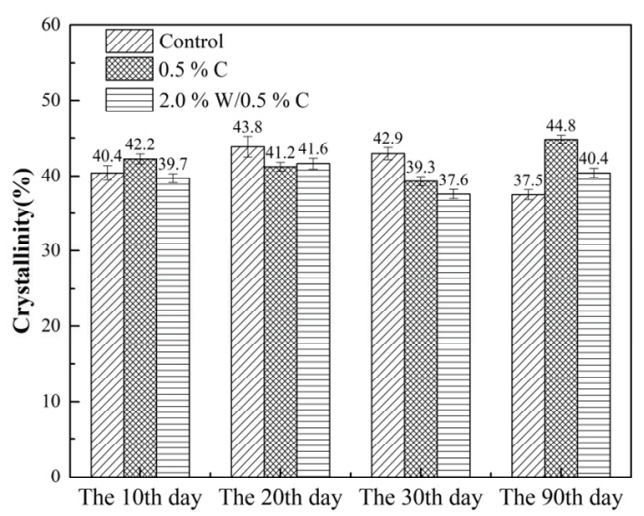

Fig. 5. Crystallinity of samples during decay process.

that of the Control. The reason is that the ligand exchange effect between CA and hemicellulose results in an increase of carboxylate anion. In this reaction, a ligand from copper ammonia complex was replaced by the samples component of carboxyl and carbonyl, carboxyl on hemicellulose was split to form carboxylic acid salt, and then form Cu-carboxylate complex with the $\mathrm{Cu}$ element. Meanwhile, the esters in lignin could hydrolyze into aromatic carboxylic acid groups under the weak alkaline conditions. (The $\mathrm{pH}$ value of $\mathrm{CuAz}$ is 8-9), and then react with copper to produce copper carboxylic acid, which also led to the reduction of the absorption peak in $1740 \mathrm{~cm}^{-1}$ (Qin, 2004). The reason why peak intensities of $1630 \mathrm{~cm}^{-1}, 1510 \mathrm{~cm}^{-1}$, and 1242 $\mathrm{cm}^{-1}$ of CA and compound system treated wood are weaker than the Control is that the phenolic hydroxyl group in lignin is the main fixation site of copper, and after the treatment by copper azole, the $\mathrm{H}$ atom of phenolic hydroxyl was replaced by $\mathrm{Cu}$ atom, forming a complex of "N-Cu-O". Meanwhile, the aromatic ester of lignin could hydrolyze into aromatic carboxylic acid group under weak alkaline conditions, and then react with copper to produce copper carboxylate (Wang et al., 2009), which reduced the intensity of absorption peak of lignin.

As shown in Fig. 4b, the peak intensities of 1740 
$\mathrm{cm}^{-1}, 1630 \mathrm{~cm}^{-1}, 1510 \mathrm{~cm}^{-1}$, and $1242 \mathrm{~cm}^{-1}$ on the 20th day of CA treated wood are higher than that of compound system treated wood and the Control, indicating that hemicellulose and lignin of CA treated wood were only degraded slightly, while those of the Control were severely destroyed.

The FTIR spectra of samples on the 30th day during the decay process is displayed in Fig. 4c. The peak intensities of $1740 \mathrm{~cm}^{-1}, 1510 \mathrm{~cm}^{-1}$, and $1242 \mathrm{~cm}^{-1}$ of CA treated wood and compound system treated wood are lower than the Control, because CA treated wood is severely degraded in middle decay stage, while the Control is badly decomposed during the early stage, which provides make a further indication that CA slows the degradation of hemicellulose and lignin.

\subsection{XRD analysis}

As presented in Fig. 5, the crystallinity of the Control on the 10th day is lower than that of the 20th day, because hemicellulose and lignin in the amorphous region were clearly degraded in the early stage of decay, causing a rise in crystallinity. Meanwhile, it was found that the crystallinity of 20-90 days decreased gradually, which suggests partial cellulose degradation, consistent with Xu et al. (2013) and Liu et al. (2018), namely white-rot fungi degraded hemicellulose and lignin first, and followed by the matrix and cellulose at the same time. Du (2004) pointed out that hemicellulose was degraded first to provide the carbon source and energy for fungal growth, and in the subsequent degradation, hemicellulose and lignin were degraded at the same time, causing degradation and destruction of the compact outer layers structure of the cell wall to further degrade hemicellulose, cellulose and lignin at the same time, and the whole degradation process was an oxidative cracking process. However, the analyses could not determine whether cellulose is degraded from 0 to the 20th day.
The crystallinities of CA and compound system treated wood $(0.5 \% \mathrm{C}, 2.0 \% \mathrm{~W} / 0.5 \% \mathrm{C})$ vary slightly during the 10th day to 30th day, but increased on the 90th day, demonstrating that hemicellulose and lignin were considerably degraded. Moreover, CA has a protective effect on cellulose. The reason is that a part of copper was absorbed by cellulose, and there is a physical adsorption effect between copper and cellulose, such as the Van der Waals force (Wang, 2007). The crystallinities of samples after decay agree with the results of mass losses. The mass losses decreased with an increase of crystallinity.

\section{CONCLUSION}

In this work, the sapwood of Populus cathay was treated by CA, paraffin water repellent, and compound systems to study in the laboratory decay resistance, with a consideration on the impact of leachability, and the decay process was investigated applying the methods of FTIR and XRD. The decay resistance levels of compound system treated wood after leaching were "very durable". Hemicellulose was degraded during the whole decay process, while a large amount of lignin was decomposed at early stage as suggested by FTIR analysis. Combined with XRD, it was found that the white-rot fungus $C$. versicolor degraded hemicellulose and lignin during early decay, and then decomposed hemicellulose, lignin and cellulose in middle and late stages. Moreover, CA could reduce the degradation speed of hemicellulose and lignin, and decrease the degradation amount of hemicellulose. These findings could provide practical references and theoretical understanding for protection of wood against decay.

\section{ACKNOWLEDGMENT}

The authors would like to thank the Beijing Training Program of Innovation and Entrepreneurship for 
Undergraduates in Being Forestry University (S201710022040) and Fundamental Research Funds for the Central Universities of China (2015ZCQ-CL-01) for financial supports.

\section{REFERENCES}

AWPA (American Wood Protection Association Standard) U1-08, 2008. Standard Method for Use Category System: Use Specification for Treated Wood, America.

AWPA (American Wood Protection Association Standard) E11-06, 2006. Standard Method for Accelerated Evaluation of Preservative Leaching, America.

AWPA (American Wood Protection Association Standard) A21-14, 2014. Standard Method for the Analysis of Wood and Wood Treating Solutions by Inductively Coupled Plasma Emission Spectrometry, America.

China Standard GB/T 13942.1-2009. Durability of wood: Method for laboratory test of natural decay resistance, China.

Bari, E., Nazarnezhad, N., Kazemi, S.M., Ghanbary, M.A T., Mohebby, B., Mohebby, B., Schmidt, O., Clausen, C.A. 2015. Comparison between degradation capabilities of the white rot fungi Pleurotus ostreatus and Trametes versicolor in beech wood. International Biodeterioration \& Biodegradation 104: 231-237.

Cao, J.Z., Yu, L.L. 2010. Properties of wood treated with water-borne preservatives. Beijing, China.

Chen, R.W., Li, H.M., Zhang, Z.X., Yan, T. 2009. Effects of waterproof additives on hygroscopic performance of preservative-treated wood. China Wood Industry 23(5): 51-53.

Chi, Y.J. 2005. FTIR analysis on function groups of David Poplar wood and lignin degraded by 6 species of wood white-rot fungi. Scientia Silvea Sinicae
41(2): 136-140.

Chinese Standard GB/T13942-2009. Durability of wood-Method for laboratory test of natural decay resistance, China.

Du, F.Y. 2004. Study on law of degradation sequence in lignocelluose by white-rot fungi. Master. Thesis, Huazhong University of Science \& Technology, China.

Fackler, K., Stevanic, J.S., Ters, T., Hinterstoisser, B., Schwanninger, M., Salmen, L. 2011. FT-IR imaging microscopy to localize and characterize simultaneous and selective white-rot decay within spruce wood cells. Holzforschung 48(65): 1-10.

Freschet, G.T., Weedon, J.T., Aerts, R., Hal, J.R.V., Cornelissen, J.H.C. 2012. Interspecific differences in wood decay rates: insights from a new short-term method to study long-term wood decomposition. Journal of Ecology 100(1): 161-170.

Huang, Y.X., Ma, E.N., Zhao, G.J. 2015. Thermal and structure analysis on reaction mechanisms during the preparation of activated carbon fibers by $\mathrm{KOH}$ activation from liquefied wood-based fibers. Industrial Crops and Products 69: 447-455.

Humar, M., Lesar, B. 2008. Fungicidal properties of individual components of copper-ethanolamine-based wood preservatives. International Biodeterioration \& Biodegradation 62(1): 46-50.

Jiang, M.L., Zhang, Y. 2008. Leachability of copperbased wood preservatives. China Wood Industry 22(3): 38-40.

Kartal, S.N., Terzi, E., Yılmaz, H., Goodell, B. 2015. Bioremediation and decay of wood treated with ACQ, micronized ACQ, nano-CuO and CCA wood preservatives. International Biodeterioration \& Biodegradation 99: 95-101.

Lee, A., Jang,J., Hwang, W., Kim, N. 2017. Decay and Termite Resistance of Yellow-Hearted Pine (Pinus densiflora for. erecta Uyeki). Journal of the Korean Wood Science and Technology 45(1): 
12-19.

Lee, H., Hwang, J., Lee, H.M., Son, D.W. 2016. Wood Decay Properties of Difference MCQ Retention Level. Journal of the Korean Wood Science and Technology 44(5): 716-725.

Lesar, B., Straže, A., Humar, M. 2011. Sorption properties of wood impregnated with aqueous solution of boric acid and montan wax emulsion. Journal of Applied Polymer Science 120(3): 1337-1345.

Li, G.Y., Huang, A.M., Qin, T.F., Huang, L.H. 2010. FTIR studies of masson pine wood decayed by brown-rot fungi. Spectroscopy and Spectral Analysis 30(8): 2133-2136.

Li, X.Y., Zhang, M.H., Shao, Z.W., Zhou, Y.J. 2017. The degree of crystallinity and the microfibril angle of acetylated wood studied by X-ray diffraction. Journal of Inner Mongolia Agricultural University (Natural Science Edition) 35(4): 121-124.

Liao, Y.Q., Zhong, H., Ma, E.N. 2016. Stress relaxation of paraffin wax emulsion/copper azole compound system treated wood. Agricultural Science \& Technology 17(5): 1243-1267.

Lin, J., Zhao, G.J., Meng, L.X., Li, Z.P. 2010. Analysis of decayed wood by fungi with X-ray Diffractometry and Fourier Transform Infrared Spectroscopy. Spectroscopy and Spectral Analysis 30(6): 1674 $-1677$.

Liu, M., Zhong, H., Ma, E.N., Liu, R. 2018. Resistance to fungal decay of paraffin wax emulsion/copper azole compound system treated wood. International Biodeterioration \& Biodegradation 129: 61-66.

Pandey, K.K., Pitman, A.J. 2003. FTIR studies of the changes in wood chemistry following decay by brown-rot and white-rot fungi. International Biodeterioration \& Biodegradation 52(3): 151-160.

Pandey, K.K., Nagveni, H.C. 2007. Rapid characterisation of brown and white rot degraded chir pine and rubberwood by FTIR spectroscopy. Holz als Rohund Werkstoff 65(6): 477-481.
Pandey, K.K., Pitman, A.J. 2010. Examination of the lignin content in a softwood and a hardwood decayed by a brown-rot fungus with the acetyl bromide method and Fourier transform infrared spectroscopy. Journal of Polymer Science Part A Polymer Chemistry 42(10): 2340-2346.

Qin, D.C. 2004. A fundamental study on the application of $\mathrm{CuAz}$ preservatives for bamboo. Doctor. Thesis, Chinese Academy of Forestry, China.

Sen, S., Tascioglu, C., Tirak, K. 2009. Fixation, leachability, and decay resistance of wood treated with some commercial extracts and wood preservative salts. International Biodeterioration \& Biodegradation 63(2): 135-141.

Tang, Z.Z., Yu, L.L., Ma, X.J., Zhu, L.Z. 2013. The impacts of several main waterborne preservative treated wood on the environmental safety. Chemistry and Industry of Forest Products 33(3): 138-142.

Tascioglu, C., Tsunoda, K. 2010. Biological performance of copper azole-treated wood and wood-based composites. Holzforschung 64(3): 399-406.

Wang, H.X., Du, F.Y., Zhang, X.Y. 2006. Selective degradation of corn straw lignocellulose by white-rot fungi. Journal of Huazhong University of Science \& Technology (Nature Science Edition) 34(3): 97-100.

Wang, J.H., Li, F.Z., Chen, F., Xu, M. 2013. Study on decay resistance and leach ability of nano copper oxide wood preservative. Forestry Science \& Technology 38(1): 25-28.

Wang, J.J., Xie, G.J., Li, X.W. 2011. Study on water repellent performance improvement of ACQ wood preservative. Guangdong Forestry Science \& Technology 27(3): 59-61.

Wang, J.M., Ma, E.N., Cao, J.Z. 2015. Metal Corrosion of Copper Azole(CA-C) / Paraffin Wax Emulsion Compound System Treated Wood. Scientia Silvea Sinicae 51(8): 74-80.

Wang, J.M., Tang, S.H., Ma, E.N., Cao, J.Z. 2014. 
Properties of compound systems of paraffin wax emulsion and copper azole and treated wood. Agricultural Science \& Technology 15(2): 222-224. Wang, J.M., Zhong, H., Ma, E.N., Cao, J.Z. 2018. Properties of wood treated with compound systems of paraffin wax emulsion and copper azole. European Journal of Wood and Wood Products 76(1): 315-323.

Wang, X.Q., Fei, B.H., Ren, H.Q. 2009. FTIR spectroscopic studies of the photo-discoloration of Chinese Fir. Spectroscopy and Spectral Analysis 29(5): 1272-1275.

Wang, Y.M. 2007. Study on application of CuAz wood/ bamboo preservative and its properties evaluation. Doctor. Thesis, Inner Mongolia Agricultural University, China.

Wang, Y.M., Ma, S.L., Feng, L.Q. 2014. The influence of oil heart treatment on wood decay resistance by Fourier infrared spectrum analysis. Spectroscopy and Spectral Analysis 34(3): 660-663.

Wang, Y.M., Wang, X.M., Liu, J.L. 2009. Study on fixation mechanism of $\mathrm{CuAz}$ preservatives in bamboo by ATR-FTIR. Spectroscopy and Spectral Analysis 29(10): 2651-2653.
Won, K., Hong, N., Jung, S., Kim, B., Byeon, H. 2017. Evaluation of Two Species of Soft Wood Decay Resistance for Heat-Treated Wood Using the Catalyst (H2SO4). Journal of the Korean Wood Science and Technology 45(2): 195-201.

Won, K.R., Hong, N.E., Park, H.M., Byeon, H.S. 2016. Evaluation of Sapwood and Heartwood Decay Resistance after Immersion-Treatment with Pyroligneous Liquor. Journal of the Korean Wood Science and Technology 44(6): 880-889.

Xu, G.Q., Wang, L.H., Liu, J.L., Wu, J.Z. 2013. FTIR and XPS analysis of the changes in bamboo chemical structure decayed by white-rot and brown-rot fungi. Applied Surface Science 280: 799-805.

Yang, S.L., Luo, S., Wu, L.Q., Li, D., Ji, N. 2016. Literature overview on leaching resistance of copper-based wood preservatives. China Wood Industry 30(1): 35-38.

Zhong, H., Wang, J.M., Tang, S. H., Ma, E.N. 2014. CA-B /New-type paraffin emulsion compound system: study on the mould preservation property of treated wood. Agricultural Science \& Technology 15(12): 2053-2056. 